\title{
Awareness regarding Iodine deficiency disorders: World Iodine deficiency day
}

\author{
Kalpana Bhushan Joshi \\ Assistant Professor, Government CON, Chhattisgarh, India \\ *Corresponding Author: Kalpana Bhushan Joshi \\ Email: verma.kalpana201@gmail.com
}

Iodine deficiency disorders are a world-wide major public health problem. More than 1.5 billion people all over world are at risk of iodine deficiency disorders. In India is estimated that more than 200 million people are at risk of iodine deficiency disorders. While the number of person suffering from goitre and other iodine deficiency disorder is above 71 million. ${ }^{3}$

In August 1992 the National goitre control programme was renamed as National iodine deficiency disorders control programme. Goal of this programme is to bring the prevalence of iodine deficiency disorders to below $5 \%$ in country. To ensure $100 \%$ consumption of adequately iodized salt (15ppm) of the household level. ${ }^{4}$

Serious iodine deficiency during pregnancy can result in stillbirth, spontaneous abortion, congenital abnormalities such as cretinism, a grave, irreversible form of mental retardation that affects people living in iodine deficient areas of Africa and Asia. The most obvious consequence of iodine deficiency disorder is goiter. ${ }^{4}$

Iodine deficiency disorders includes such as goiter, subnormal intelligence, delayed motor milestones, strabismus, nystagmus, neuromuscular weakness, endemic cretinism, still birth, hypothyroidism, defect in vision, hearing and speech spasticity, mental retardation and intra uterine death. ${ }^{9}$

In today's scenario $1 / 3^{\text {rd }}$ of world population is at risk of iodine deficiency disorders. According to WHO, around 54 countries are still iodine deficient. Over 740 million people in 130 countries are facing the health problem. In India more than six corer people are suffering from iodine deficiency disorders including endemic goiter and 88 lakh people from mental motor handicaps. Iodine is a trace mineral required for optimal mental and physical development and is a key constituent of thyroid hormones. Iodine deficiency is the single largest cause of preventable brain damage globally. Iodine deficiency disorders include goiter, cretinism, hypothyroidism, abortion, still birth, brain damage, learning disability, mental retardation, psychomotor defect, hearing and speech impairment. Iodine is required for school going children, adolescents and pregnant/lactating women is 120,150 and 200 micrograms daily for normal human growth and development. Iodine is required for the synthesis of the thyroid hormones, thyroxine (T4) and tri iodothyronine and essential for the normal growth development and wellbeing of all humans. Consumption of goiterogenic foods and inadequately iodized household salt can also increase the risk of iodine deficiency. ${ }^{6}$

The most recent global estimate, 1.88 billion people are at risk of iodine deficiency and 241 million children have inadequate iodine intake. ${ }^{7}$

A similar study conducted in 1956 in Kangra Valley; Himachal Pradesh in North India established iodine deficiency as a major cause of endemic goiter and demonstrated a significant decline in goiter prevalence in the areas receiving iodized salt. ${ }^{8}$

The children born in iodine deficient regimen on an average have 13.5 intelligent quotients (IQ) points lesser than children born in iodine sufficient regions. ${ }^{4}$

According to central state health directorates and ICMR and medical institutes at the 325 district surveyed in India. 263 districts are IDD is above $10 \%$ in the population. ${ }^{1}$

As per National Nutrition Monitoring Board (NNMB) in 2000-2001 in rural area of Kerala, Tamilnadu, Karnataka, Andhra Pradesh, Maharashtra, Madhya Pradesh, Orissa, West Bengal, the overall prevalence of total goitre rate among 6 to 12 years old children was about $4 \%$. The prevalence of goitre is highest in Maharashtra $11.9 \%$ and west Bengal $9 \% .^{2}$

Globally two billion people are at risk of iodine deficiency disorders due to insufficient iodine intake. Nearly 266 million school aged children world-wide have insufficient iodine intake, out of 130 countries which reported data for Iodine deficiency disorders in 2006 comprising $91 \%$ of the total global populations. Iodine deficiency disorders were a public health problem in 47 countries. $^{5}$ 
Iodine deficiency disorders linked to iodine deficient soil due to glaciations, flooding, rivers changing course and deforestation the iodine present in top soil is constantly leached. This turn leads to deficiency of iodine in crops grown on iodine deficient. Soil with consequently low iodine in the diet for livestock and humans. According to NFHS 2015-16 shown that 93\% of house hold are using iodized salt as compare to $73 \%$ in NFHS -3 (2005-06). ${ }^{10}$

"Universal use of iodized salt is a simple inexpensive method of prevention of Iodine deficiency disorders." The recommended salt iodine fortification level of 15 ppm provides 150 microgram of iodine per day assuming daily salt consumption of $10 \mathrm{gm}$. Iodine fortification at this level meets the recommended daily requirements and is also well within the upper safety limit of 1000 microgram by WHO. ${ }^{3}$

The consumption of adequately iodated salt at household level has been increased 93\% (as per NFHSIII report 2015-16) as compare to 73\% (as per NFHS -3 report, 2005-06). ${ }^{11}$

The children born in iodine deficient regions on an average have 13.5 intelligent quotient (IQ) points lesser than children born in iodine sufficient regions. ${ }^{4}$

The aim of this day was to generate awareness of the adequate use of iodized salt, iodine rich diet, deficiency disorders and its treatments. We Government college of Nursing, Durg, Chhattisgarh celebrated global iodine deficiency disorder control day 2019, at college and District Hospital, Durg. The programme commenced at $10 \mathrm{am}$ to $1 \mathrm{pm}$. The formal programme was followed by a essay competition, poster competition, slogan and role play B.Sc. Nursing students presented in district hospital, Durg. In role- play students gave awareness regarding iodine deficiency disorder and its treatment and prevention. At the end of programme certificate of appreciation distributed.

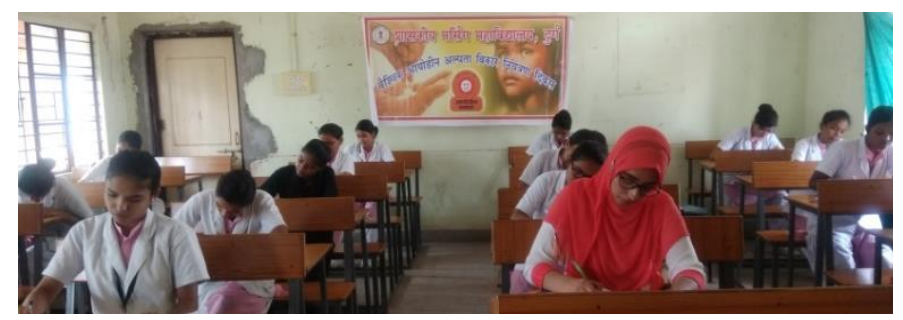

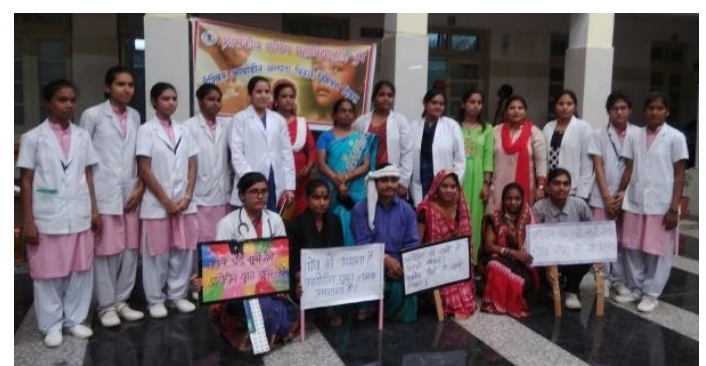

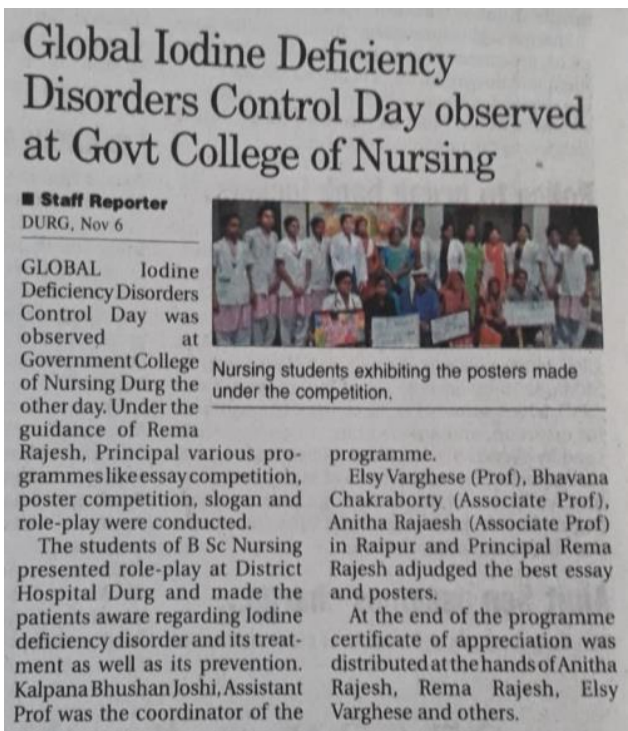

\section{Conclusion}

Emphasis on a sustainable iodine intervention programme targeted at population level, particularly at females is mandatory. In general that iodine deficiency disorder was a serious public health problem in India. India was one of the first countries in the world to start a public health programme to address iodine deficiency disorders based on salt iodization.

\section{Source of Funding}

None.

\section{Conflict of Interest}

None.

\section{References}

1. New Delhi: Ministry of health and Family welfare, Government of India; 2011. (Accessed on July 1, 2011). Dept. of Health and Family welfare. Annual report 201011. Available from http:// www. Mohfw. Nic. In/ how file. Php. Lid: 767.

2. Prevalence of micronutrients deficiencies. Hyderabad: NNMB Technical report No. 2. ICMR, National Institute of Nutrition; 2003. (accessed on July, 2011). National Nutrition Monitoring Bureau. 
http://www.nnmbindia.org/NNMB: 20 MND: 20 Report 2004.

3. Geneva: World Health Organization; 2007. ICCIDD, UNICEF, WHO. Assessment of iodine deficiency disorders and monitoring their elimination: a guide for programme manager.

4. Bleichrodt N, Born MP. A metanalysis of research on iodine and its relationship to cognitive development. In: stanburg TB, Newyork: cognizant communication corporation; 1994. pp. 195-200.

5. De Benoist B, Mclean E, Andersson M, Rogers L. Iodine deficiency in 2007: global progress since 2003. Food NutrBull. 2008;29:195-202.

6. Demelash H, Gashaw K, Melese A. Prevalence of goiter and associated factors among primary school going children aged 6-12 years old in Goba town, south east, Ethiopia. Int J Nutr Food Sci. 2015:4(3):381-7.

7. Andersson M, Karumbunathan V, Zimmermann MB. GLOBAL IODINE STATUS IN 2011 and trends over the pastdecade. J Nutr. 2012:142:744-50.
8. Sooch SS, Ramalingaswami V. Preliminary report of an experiment in the Kangra Valley for the prevention of Himalayan endemic goitttre with iodized salt. Bull World Health Org. 1965;32:299-315.

9. Park K. Nutrition and health. In: text book of preventive and social medicine. $20^{\text {th }}$ ed. Jabalpur. Banasidas Bahnot; 2009; pp. 539-40, 557-8.

10. nhm.gov.in/nrhm-components/ national disease control programmes_ndcps/iodine-deficiency - disorders.

11. nhm.gov.in/ NHP India, National Health Portal. Nrhmcomponents/national.disease control- programmesndcp/iodinedeficiencydisorers.html.published:oct.21,2018. NHP admin.

How to cite: Joshi KB. Awareness regarding Iodine deficiency disorders: World Iodine deficiency day. $J$ Community Health Manag. 2020;7(1):36-8. 